\title{
SUPPLEMENT
}

\author{
Olcay E. Kiroğlu ${ }^{1}$ \\ Kübra Demirkol ${ }^{2}$ \\ Fatih Berktaş3 ${ }^{3}$ \\ Arash A. Yeganit \\ Aysegül. Kirpik 5 \\ Erkan Maytalman 6 \\ Mabmut Ünverdi ${ }^{7}$ \\ Fazilet $A k s u^{8}$
}

${ }^{1}$ Assistant professor, Cukurova University, Faculty of Medicine, Department of

Pharmacology

${ }^{2}$ Family Medicine Resident, The Ministry of

Health of Ankara Numune Hospital,

Departman of Family Medicine

${ }^{3}$ Graduate student, Cukurova University,

Faculty of Medicine, Department of

Pharmacology

${ }^{4}$ Doctoral student, Cukurova University,

Faculty of Medicine, Department of

Pharmacology

${ }^{5}$ Graduate student, Cukurova University,

Faculty of Medicine, Department of

Pharmacology

${ }^{6}$ Doctoral student, Cukurova University,

Faculty of Medicine, Department of

Pharmacology

${ }^{7}$ Fifth Grade Student, Cukurova University,

Faculty of Medicine

${ }^{8}$ Professor, Cukurova University, Faculty of

Medicine, Department of Pharmacology

Clin Invest Med 2016; 39 (6): S14-S20.

\section{Dipyrone ameliorates behavioural changes induced by unpredictable chronic mild stress: gender differences}

\begin{abstract}
Purpose: Antidepressant effects of analgesics have been investigate in both clinical and experimental studies. The purpose of this study was to investigate if the analgesic-antipyretic drug, dipyrone, also had antidepressant-like effects.

Methods: Depression-like effects were investigated in an unpredictable chronic mild stress (UCMS) model in both male and female mice. Cage changes, light-dark cycle reversal, cage tilting, wet floor, empty cage, foreign material on the floor and predator sounds were used to induce light stress at different times for six weeks. Dipyrone was administered intraperitoneally beginning from the third week. Splash, rota-rod (RR) and forced swimming (FST) tests were performed at the seventh week as behavioural tests to evaluate the antidepressant-like effects of dipyrone. Coat state score (CSS) and weights of animals were recorded at seventh weeks. Results were analyzed using one or two-way ANOVA followed by the Bonferonni post hoc test.
\end{abstract}

Results: Weight of UCMS-exposed mice did not change compared with controls; however, significant changes were observed in CSS in both sexes of stressed mice $(p<0.05)$. RR latency decreased and immobility time enhanced in FST test in both sexes of stressed mice $(p<0.05)$. Grooming behaviour was not different between the groups in female mice, but different in male mice in the splash test. Dipyrone did not produce a significant change in CSS in the UCMS-exposed group but reversed the latency time and immobility time to normal values in both sexes of mice and augmented the number of grooming behaviour only in stressed male mice.

Conclusion: These results indicate that dipyrone produce antidepressant-like effects to some symptoms of UCMS according to gender.

\section{Correspondence to:}

Fazilet Aksu

Cukurova University, Faculty of Medicine, Department of Pharmacology Adana

E-mail: faziletaksu@gmail.com 
Inhibition of central cyclooxygenase system and activation of opioid and cannabinoid systems are important mechanism suggested for dipyrone, a strong analgesic and antipyretic agent [1-3]. Serotonergic-noradrenergic system, arginine-NO-cGMP pathway, neuronal potassium channels and inflammatory cytokine levels have been suggested as possible mechanisms for the analgesic action of dipyrone [4-6]. Other central effects, distinct from this analgesic effect, have been evaluated. Dipyrone has been shown to produce anticonvulsant effect in rats exposed to the audiogenic and electroshock-induced seizures [7]. Dipyrone was also found to reverse the mechanical allodynia induced by CFA, and reduce the immobility time in tail suspension test in a study that compares the depression-like behavior of analgesics and bupropion in a model of chronic inflammation-related depression in mice [8].

Depression is a serious disorder that affects a large number of people worldwide. It has been hypothesized that functional deficiency of the brain monoaminergic transmitters is the major cause of depression. Conventional treatment of depression with antidepressants, such as monoamine re-uptake inhibitors, and cognitive behavioural therapy can be ineffective in a considerable number of patients. Moreover, antidepressant therapy has a variety of undesirable side effects such as sedation, decrease of blood pressure, increase of weight, indigestion or sexual dysfunction. These symptoms often results in patients' poor compliance, leading to a discontinuation of medication with recurrence of depressive symptoms and increased suicidal risk [9]. To investigate new, alternative, causative and/or easy available treatment strategies beyond conventional methods for prevention and treatment of depression would be an instructive study for future psychiatric care.

Mechanisms suggested for analgesic effects of dipyrone, such as change in proinflammatory cytokines levels, activation of ion channels and activity of endogenous opioid and cannabinoid systems, are involved in pathophysiology of depressive disorders also. On the other hand, depression and pain are mostly comorbid conditions - evident since pain is known to induce depression and depression to induce pain [10]. A drug, which both relieves pain and ameliorates depressive symptoms, can be an alternative treatment for patinets with comorbid depression and pain. Recently some analgesics have been recommended for comorbid cases. To this end, we studied the antidepressant-like effect of dipyrone in both genders of mice using an unpredictable chronic mild stress (UCMS) model in mice.

\section{Materials and Methods}

Animals

Swiss Albino mice of either sex weighing 20-25 g, obtained from Çukurova University Experimental Research and Application Center of Medical Sciences, were used in all experiments. They were kept in the standard laboratory conditions (12 h light-dark cycle, lights on at 08:00 am, $24 \pm 1^{\circ} \mathrm{C}$ ) for 1 week before the onset of the experiments. Mice received food and water ad libitum. All procedures were carried out following a protocol approved by Çukurova University, Faculty of Medicine Animal Ethic Committee.

\section{Experimental groups and drug administration}

Mice were divided into non-stress (control) and UCMS-exposed (stressed) groups. Each group divided to subgroups according to gender. Control mice were housed as three mice per cage during the experiment in a separate room. Stressed mice were singly housed in their home cages. At the end of the two-week long drug-free UCMS, stressed mice were divided to three groups: I. stressed+vehicle; II. stressed +100 mg dipyrone; and, III. stressed $+200 \mathrm{mg}$ dipyrone $(\mathrm{n}=8$ per group). Drug and vehicle were administered intraperitoneally (i.p.) each day at $13.30 \mathrm{pm}$ in a volume of $0.1 \mathrm{ml} / 10 \mathrm{~g}$ body weight for 5 weeks. At the end of the UCMS regimen, behavioural tests were performed. Dipyrone was purchased from Sigma Chemical Company, dissolved in $0.9 \%$ saline and administered 100 or $200 \mathrm{mg} / \mathrm{kg} /$ per day. Drug doses and dosing times were chosen according to the previous studies [11].

\section{Unpredictable Chronic Mild Stress Model}

UCMS-exposed animals exhibited several neurobehavioral alterations, resembling the symptoms of chronic human depression, and are widely employed for preclinical screening of antidepressants. This model was originally described for rats [12] and mice [13] and consists of repeated mild physical and psychological stressors. In the present study, unpredictable stressors were applied according to previous studies with minor modifications. Mice were subjected several times a day for 6 weeks to one of the following stressors: exposure to a foreign object (stone); damp sawdust; sawdust changing; placement in an empty cage; placement in an empty cage with water on the bottom; switching the cages; cage tilting $\left(45^{\circ}\right)$; predator sounds for $15 \mathrm{~min}$; inversion of light/dark cycle; and, lights on for a short time during the dark phase. For ethical reason, the stress procedure did not involve deprivation of food and water 
or immobilization. Except social stress, mice were exposed to the stressors in their own cage. To prevent habituation and provide an unpredictable feature, all stressors and/or sequences were administered at different time points every week [14, 15].

\section{Behavioural Tests}

Coat state (CS) and body weight (BW) are important indicators of the general state in mice. It has already been reported that the UCMS procedure induces a degradation of the animal's general physical state that can be counteracted by a chronic antidepressant treatment but not by acute administration $[16,17]$. CS and BW of the animals were recorded on each Monday before and during the experiments. The evaluation of the CS was carried out by assessment of eight different body parts: head (including eyes and nose); neck; dorsal coat;ventral coat; tail; forepaws; hind paws; and, genital region $[16,18]$. A score of " 0 " for a coat in a good state or a score of " 1 " for a dirty coat were given for each of these areas. Dirty state is characterized by fluffy, greasy, less dense coat or piloerection. In addition, conjunctivitis and rhinitis were observed. Total scores were obtained from the sum of the score of each body parts. In all experiments, total score of the last week of the stress regimen were presented. The observers who scored the CS were unaware of the treatment condition.

Motor coordination has traditionally been assessed in mice and rats by the rota rod (RR) test, in which the animal is placed on the rotating bar at a rotating speed of 18 r.p.m. The animal must walk forwards to remain upright and not fall off for 5 minute [19].
The splash test (ST) is validated animal model that investigates the motivational behaviour of animals. UCMS decreases grooming behaviour triggered by the $\mathrm{ST}$ and this phenomenon is considered to be similar to the apathy observed in depressive patients. Grooming behaviour include cleaning of the fur of the animal by licking or scratching. Grooming times were recorded by observing nose/face grooming (strokes along the snout), head washing (semicircular movements over the top of the head and behind the ears) and body grooming (body fur licking). A sucrose solution (10\%) was sprayed on the neck and dorsal coat of mice. The total number of grooming was recorded for $5 \mathrm{~min}$ after vaporization of the sucrose solution [18]. The observer was unaware of the treatment conditions.

Forced swimming test (FST) was developed by Porsolt et al. to determine the effect of substances that have antidepressant potential. Animals were placed in a tank containing water at a temperature of $23 \pm 2^{\circ} \mathrm{C}$ for $6 \mathrm{~min}$. A decrease of immobility was considered an antidepressant-like effect [20]. For a period of $6 \mathrm{~min}$, agitation and immobility time of the animals was computed. Immobility time was measured for a period of last 4 min (the first two minutes were not recorded).

\section{Statistical analysis}

All data were expressed as means \pm standard error of the mean (S.E.M.). The results were analyzed using a one or two-way analysis of variance followed by the Bonferonni post hoc test and unpaired t-test corrected when appropriate. Differences between groups were considered significant when $\mathrm{P}<0.05$.
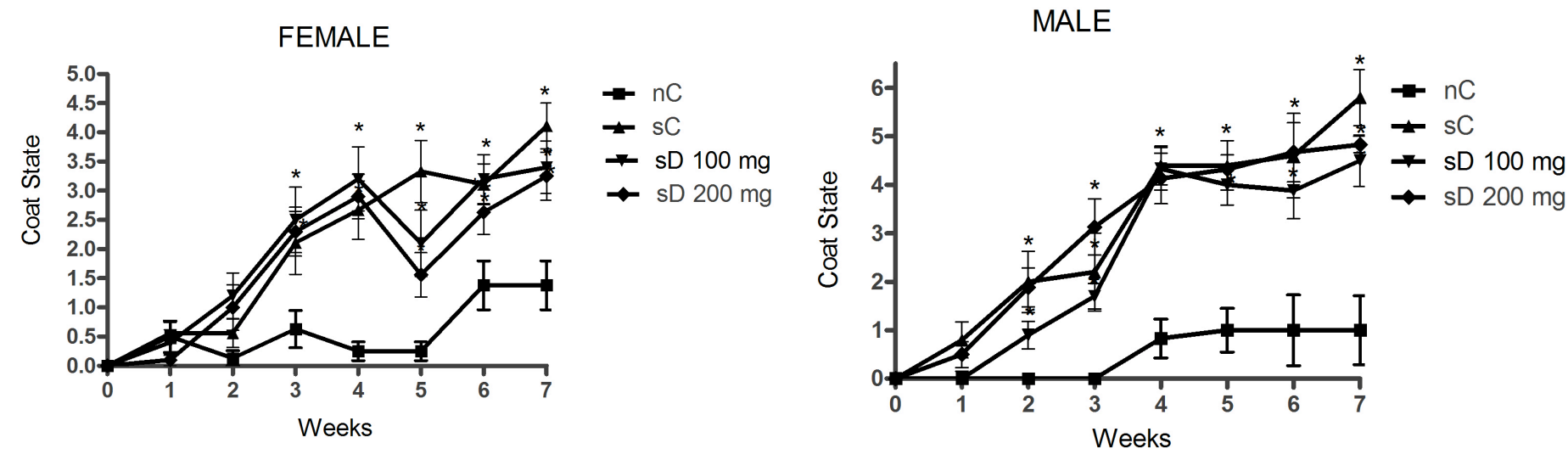

FIGURE 1. Effects of dipyrone (100 and $200 \mathrm{mg}$ i.p., for 5 weeks) in stressed female (A) and male (B) groups during UCMS on coat state of the animals ( $\mathrm{n}=8$ per group). ${ }^{*} \mathrm{p}<0.05$ significantly different from the non-stressed control group using two-way ANOVA. nC $=$ non-stressed control (vehicle) group, $\mathrm{sC}=$ stressed control (vehicle) group, $\mathrm{sD} 100 \mathrm{mg}=$ stressed dipyrone $100 \mathrm{mg}$ group, $\mathrm{sD} 200 \mathrm{mg}=\mathrm{stressed}$ dipyrone 200 mg group. 


\section{Results}

\section{Effect of dipyrone on coat state and body weight}

The coat state scores (CSS) of control, stressed and stressed+dipyrone-administered female and male mice were shown in Figure 1A (female) and 1B (male). A significant difference between the CSS of the control and the UCMS-exposed group was observed in female mice from the third week $(\mathrm{p}<0.05)$ and male mice from the second week. Dipyrone (100 and $200 \mathrm{mg} / \mathrm{kg}$ doses) were administered to UCMS-exposed groups on the second week. Neither 100 nor $200 \mathrm{mg} / \mathrm{kg}$ doses of dipyrone produced significant changes in CSS in the UCMS-exposed group in either the female and male mice groups. There was no statistically difference in the body weights in the female and male groups across all experimental groups from the beginning of the first week until to the end of the UCMS (data not shown).

\section{Effect of dipyrone on locomotion in rota rod test}

In the rota rod (RR) test, the stressed group showed significantly less latency to fall from the rod as compared with the control group in female mice group (89.4 \pm 14.2 and $115 \pm 2$ $\mathrm{sec}$, respectively, $\mathrm{p}<0.05)$. Dipyrone $(100$ and $200 \mathrm{mg} / \mathrm{kg}$ ) significantly enhanced the stress group's latency values in female mice $(114.4 \pm 4.3,118.8 \pm 0.8$ and $89.4 \pm 14.2 \mathrm{sec}$, respectively, $\mathrm{p}<0.05$, Figure 2$)$. Stressed male mice group also showed significant differences from control group (64.4 \pm 16.7 sec, $115 \pm 5 \mathrm{sec}$, respectively, $\mathrm{p}<0.05)$. Dipyrone at 100 and 200 $\mathrm{mg} / \mathrm{kg}$ doses significantly enhanced the stress group's latency values $(111.2 \pm 5.3,113.6 \pm 4.3$ and $64.4 \pm 16.7 \mathrm{sec}$, respectively, $\mathrm{p}<0.05$, Figure 2).

\section{Effect of dipyrone on grooming behaviour in splash test}

The effects of UCMS and drug treatment on the total number of grooming in splash test are shown in Figure 3. There were no significant differences between control, stressed and dipyrone groups in female mice $(166.5 \pm 12.6,155.4 \pm 15.0,150.4 \pm 11.0$ and $152.8 \pm 13.4 \mathrm{sec}$, respectively, Figure 3$)$. But male mice showed different behaviour than females: control male mice groomed significantly more than stressed males $(181.5 \pm 19.25$ and $122.6 \pm 12.86 \mathrm{sec}$, respectively, $\mathrm{p}<0.05)$. Dipyrone significantly augmented the number of grooming behaviour in stressed male mice at 100 and $200 \mathrm{mg} / \mathrm{kg}$ doses $(183.4 \pm 12.9$ and $216.5 \pm 24.5 \mathrm{sec}, \mathrm{p}<0.05$, respectively, Figure 3 ).

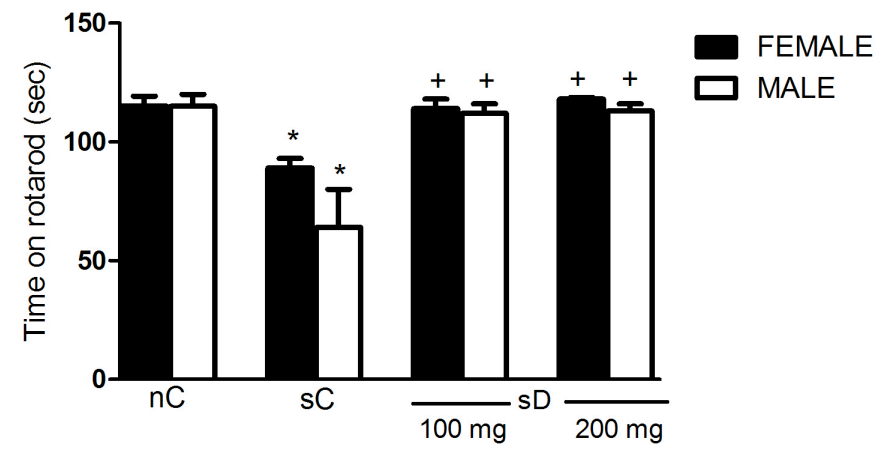

FIGURE 2. Effects of dipyrone (100 and $200 \mathrm{mg}$ i.p., for 5 weeks) in stressed female and male groups during UCMS on rota rod test $\left(\mathrm{n}=8\right.$ per group). ${ }^{*} \mathrm{p}<0.05$ significantly different from the non-stressed control group and $+\mathrm{p}<0.05$ significantly different from stressed control group in female and male groups using one-way ANOVA. $\mathrm{nC}=$ non-stressed control (vehicle) group, $\mathrm{sC}=$ stressed control (vehicle) group, sD $100 \mathrm{mg}=$ stressed dipyrone $100 \mathrm{mg}$ group, sD $200 \mathrm{mg}=$ stressed dipyrone $200 \mathrm{mg}$ group.

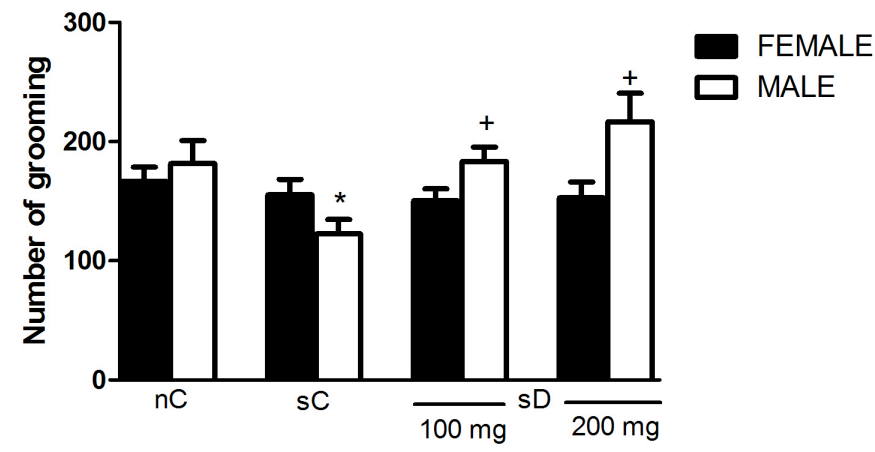

FIGURE 3. Effects of dipyrone (100 and $200 \mathrm{mg}$ i.p., for 5 weeks) in stressed female and male groups during UCMS on splash test ( $\mathrm{n}=8$ per group). ${ }^{*} \mathrm{p}<0.05$ significantly different from the non-stressed control group and $+p<0.05$ significantly different from stressed control group in male groups using one-way ANOVA and unpaired t-test. $\mathrm{nC}=$ non-stressed control (vehicle) group, $\mathrm{s} \mathrm{C}=$ stressed control (vehicle) group, $\mathrm{sD} 100 \mathrm{mg}=$ stressed dipyrone $100 \mathrm{mg}$ group, sD $200 \mathrm{mg}$ = stressed dipyrone $200 \mathrm{mg}$ group. 


\section{Effect of dipyrone on immobility time in the forced swimming test}

Females in the stressed group showed enhanced immobility time compared with the control group in the FST $(194.6 \pm 10.9$ and $124.3 \pm 25.7 \mathrm{sec}$, respectively, $\mathrm{p}<0.05)$. Dipyrone significantly reduced the immobility time (119.4 $\pm 30.0,130.4 \pm 20.6,194.6 \pm 10.9$, respectively, $p<0.05$, Figure 4). Stress-exposed male mice showed significantly higher immobility times than those in the control group $(199.8 \pm 5.2$ and $124.8 \pm 10.6 \mathrm{sec}$, respectively, $\mathrm{p}<0.05)$ and dipyrone reduced the immobility time significantly $(145.8 \pm 11.9,143.4 \pm 10.4$ and $199.8 \pm 5.2 \mathrm{sec}$, respectively, $\mathrm{p}<0.05$, Figure 4).

\section{Discussion}

The antidepressant effects of many analgesic drugs have been observed in clinical and experimental animal studies [21-27]. Tramadol and some opioid agonists have been declared to improve depressive symptoms [22, 23]. Celecoxib and piroxicam have been shown to display antidepressant effect in human and animal studies [8, 24-26]. Acute administration of paracetamol has been shown to cause antidepressant-like effects and display synergistic effect with fluoxetine in FST and tail suspension tests without affect locomotor activity [27]. Dipyron and paracetamol have been proposed to reveal similar analgesic mechanism such as inhibition of COX enzymes in the brain, interaction with endogenous opioid and cannabinoid systems, arginine-nitric oxide-cGMP pathway, 5-HT activation [6]. Impairments in these endogenous systems also produce depressive states as indicated in clinically and experimentally studies [28].

In the present study, development of depressive-like symptoms following UCMS was evaluated via CS, RR, ST and FS tests. CS, RR and FS tests revealed that depressive behaviours occurred in both sex of UCMS-exposed mice. However, changing in grooming behaviour in the ST was seen only in UCMS-exposed male mice. Our study showed similarities [15, 29-31] and discrepancies [32-33] with earlier studies evaluating the physical and behavioural effects of UCMS. Discrepancies may be attributed to differential strain and sex susceptibility to UCMS, to variable protocols implemented in different laboratories, to differences of environmental conditions and to experimenter bias. Yalçın showed that $\mathrm{Balb} / \mathrm{c}$ mice were more susceptible to UCMS-exposure than Swiss strain mice [32]. Ibarguen-Vargas et al. subjected mice from seven different strains to a 9-week UCMS regimen and concluded that the behavioural symptoms seen in depressed mice and the efficacy of

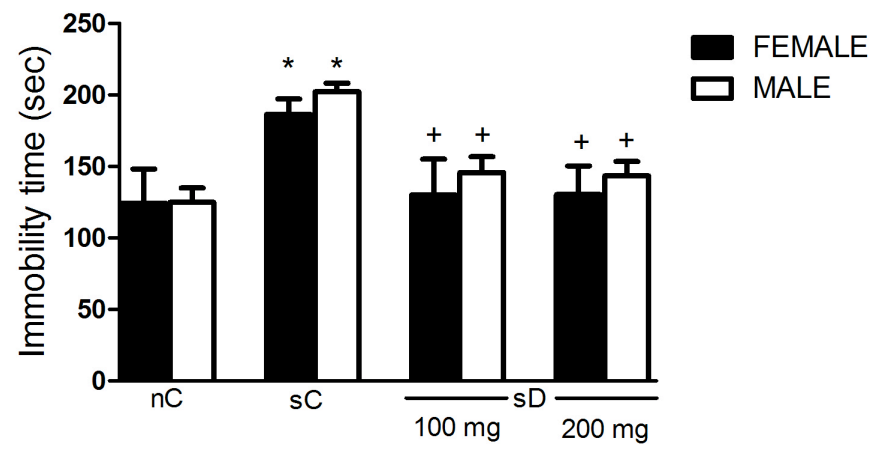

FIGURE 4. Effects of dipyrone (100 and $200 \mathrm{mg}$ i.p., for 5 weeks) in stressed female and male groups during UCMS on forced swimming test ( $\mathrm{n}=8$ per group). ${ }^{*} \mathrm{p}<0.05$ significantly different from the non-stressed control group and $+\mathrm{p}<0.05$ significantly different from stressed control group in female and male groups using one-way ANOVA and unpaired t-test. $\mathrm{nC}=$ non-stressed control (vehicle) group, $\mathrm{sC}=$ stressed control (vehicle) group, $\mathrm{sD} 100 \mathrm{mg}=$ stressed dipyrone $100 \mathrm{mg}$ group, $\mathrm{sD} 200 \mathrm{mg}=$ stressed dipyrone 200 mg group.

antidepressant drugs are related to strain [33]. We used Swiss mice in our experiments so discrepancies with the other studies may be related to mouse strain.

Gender is another factor that influences the behavioural effects of UCMS. Stanley et al. [34] indicated that behavioural impairments, elevations in plasma cortisol and plasma markers of oxidant stress and inflammation demonstrated in female mice in response to chronic unresolvable stresses were significantly greater than those demonstrated in male mice. Bowman et al [35] suggested that sex differences must be taken into account when investigating or describing stress and associated squeal according to their study on chronic stress effects on memory. Similar results revealing gender-related variability in vulnerability to UCMS treatment and activity of antidepressants have been demonstrated in the literature [36, 37].

Our results indicate that male mice were more susceptible to grooming behaviour and dipyrone was effective to increase grooming in ST. Increased latency to groom and reduced total grooming time in the sucrose $S T$ is representative of the core symptom of depression, anhedonia. These results show some similarity to earlier results indicating that the antidepressant potential of ketamine was longer lasting in males, as assessed in the ST [38]; however, our ST results contradict other studies that report that either both sexes or only female mice are 
susceptible to ST. These discrepancies between various studies may be related to strain differences, as mentioned above.

In the present study, a progressive decline in CS scores was observed in all UCMS animals. This behaviour may parallel the lack of motivation to or loss of interest in performing everyday tasks, such as the maintenance of minimal personal care. Intriguingly, dipyrone did not produce any effect on this decline in CS in all UCMS-treated animals. In many studies, CS decline induced by UCMS was attributed to hippocampal degeneration. In a previous study, hippocampal irradiation completely abolished the effect of fluoxetine, which was able to reverse the CS degradation induced by UCMS non-irradiated mice [39]. From the results of rodent studies which suggest neurogenesis is necessary for mediating the salutary effects of antidepressants [40], we may argue that dipyrone, at the doses used in the present study, was ineffective ing producing neurogenesis in hippocampal neurons. On the other hand, dipyrone produced significant improvements in locomotion and immobility time - which were impaired by UCMS in both genders of mice.

Altogether, our results indicate that the analgesic and antipyretic drug dipyrone has antidepressant-like effects in the UCMS model. This study supports a proof-of-concept concerning the use of analgesics the treatment of depression; however, more studies are needed to understand whether combined treatment with dipyrone and antidepressant drugs could be clinically beneficial in relation to the delayed therapeutic effect of classical antidepressant. Also, further studies are needed to elucidate the mechanisms of the antidepressant-like effects of dipyrone and to investigate in terms of side effects. This, in turn, could help provide better therapeutic management for patients with depression and pain comorbidity.

\section{References}

1. Chandrasekharan NV, Dai H, Roos KL, Evanson NK, Tomsik J, Elton TS, Simmons DL. COX-3, a cyclooxygenase-1 variant inhibited by acetaminophen and other analgesic/antipyretic drugs: cloning, structure, and expression. Proc Natl Acad Sci USA. 2002; 99:13926-31.

2. Escobar W, Ramirez K, Avila C, Limongi R, Vanegas H, Vazquez E. Metamizol, a non-opioid analgesic, acts via endocannabinoids in the PAG-RVM axis during inflammation in rats. Eur J Pain. 2012; 16:676-89.

3. Vanegas H, Tortorici V. Opioidergic effects of nonopioid analgesics on the central nervous system. Cell Mol Neurobiol. 2002; 22:655-61.

4. Lorenzetti BB, Ferreira SH. Activation of the arginine-nitric oxide pathway in primary sensory neurons contributes to dipyrone-induced spinal and peripheral analgesia. Inflamm Res. 1996; 45(6):308-11.

5. dos Santos GG, Dias EV, Teixeira JM, Athie MC, Bonet IJ, Tambeli CH, Parada CA. The analgesic effect of dipyrone in peripheral tissue involves two different mechanisms: Neuronal KATP channel opening and CB1 receptor activation. Eur J Pharmacol. 2014; 741:124-31.

6. Rezende RM, Franc DS, Menezes GB, dos Reis WGP, Bakhle YS, Francischi JN. Different mechanisms underlie the analgesic actions of paracetamol and dipyrone in a rat model of inflammatory pain. British Journal of Pharmacology. 2008; 153:760-68.

7. Doretto MC, Garcia-Cairasco N, Pimenta NJG, Souza DA, Tatsuo MAKF. Dipyrone, a novel anticonvulsant agent? Insights from three experimental epilepsy models. Neuroreport. 1998; 9:2415-21.

8. Maciel IS, Silva RB, Morrone FB, Calixto JB, Campos MM. Synergistic effects of celecoxib and bupropion in a model of chronic inflammation-related depression in mice. PLoS One. 2013; 8(9):e77227.

9. Undine E. Lang Stefan Borgwardt, Molecular Mechanisms of Depression: Perspectives on New Treatment Strategies, Cellular Physiology and Biochemistry, 2013; 31:761-777

10. Blackburn-Munro G, Blackburn-Munro RE. Chronic pain, chronic stress and depression: coincidence or consequence? J Neuroendocrinol. 2001; 13:1009-23.

11. Akman H., Aksu F., Gültekin İ., Özbek H., Oral U., Doran F., Baysal F. A possible central antinociceptive action of dipyrone in mice. Pharmacology. 1996; 53:71-8.

12. Willner P, Towell A, Sampson D, Sophokleous S, Muscat R. Reduction of sucrose preference by chronic unpredictable mild stress, and its restoration by a tricyclic antidepressant. Psychopharmacology (Berl). 1987; 93(3):358-64.

13. Kopp C, Vogel E, Rettori MC, Delagrange P, Misslin R. The effects of melatonin on the behavioural disturbances induced by chronic mild stress in C3H/He mice. Behav Pharmacol. 1999; 10(1):73-83.

14. Yalcin I, Aksu F, Bodard S, Chalon S, Belzung C. Antidepressant-like effect of tramadol in the unpredictable chronic mild stress procedure: possible involvement of the noradrenergic system. Behav Pharmacol. 2007; 18(7):623-31.

15. Mutlu O, Gumuslu E, Ulak G, Celikyurt IK, Kokturk S, Kır HM, Akar F, Erden F. Effects of fluoxetine, tianeptine and olanzapine on unpredictable chronic mild stress-induced depression-like behavior in mice. Life Sci. 2012; 91(25-26):1252-62.

16. Ducottet C, Griebel, Belzung C. Effects of the selective nonpeptide corticotropin-releasing factor receptor 1 antagonist antalarmin in the chronic mild stress model of depression in mice. Prog Neuropsychopharmacol Biol Psychiatry. 2003; 27:625-31. 
17. Santarelli L, Saxe M, Gross C, Surget A, Battaglia F, Dulawa S, Weisstaub N, Lee J, Duman R, Arancio O, Belzung C, Hen R. Requirement of hippocampal neurogenesis for the behavioral effects of antidepressants. Science. 2003; 301(5634):805-9.

18. Isingrini E, Camus V, Le Guisquet AM, Pingaud M, Devers S, Belzung C. Association between repeated unpredictable chronic mild stress (UCMS) procedures with a high fat diet: a model of fluoxetine resistance in mice. PLoS One. 2010; 28:5(4).

19. Vaught JL, Pelley K, Costa LG, Setler P, Enna SJ. A comparison of the antinociceptive responses to the GABA-receptor agonists THIP and baclofen. Neuropharmacol. 1985; 24(3):211-6.

20. Porsolt RD, Le Pichon M, Jalfre M. Depression: a new animal model sensitive to antidepressant treatments. Nature. 1977; 266(5604):730-2.

21. Köhler O, Benros ME, Nordentoft M, Farkouh ME, MD, Iyengar RL, Mors O, Krogh J. Effect of anti-inflammatory treatment on depression, depressive symptoms, and adverse effects. A systematic review and meta-analysis of randomized clinical trials. JAMA Psychiatry. 2014; 71(12):1381-91.

22. Barber J. Examining the use of tramadol hydrochloride as an antidepressant. Exp Clin Psychopharmacol. 2011; 19(2):123-30.

23. Rojas-Corrales MO1, Berrocoso E, Gibert-Rahola J, Micó JA. Antidepressant-like effects of tramadol and other central analgesics with activity on monoamines reuptake, in helpless rats. Life Sci. 2002; 72(2):143-52.

24. Nery FG1, Monkul ES, Hatch JP, Fonseca M, Zunta-Soares GB, Frey BN, Bowden CL, Soares JC. Celecoxib as an adjunct in the treatment of depressive or mixed episodes of bipolar disorder: a double-blind, randomized, placebo-controlled study. Hum Psychopharmacol. 2008; 23(2):87-94.

25. Mohammadinejad P, Arya P, Esfandbod M, Kaviani A, Najafi M, Kashani L, Zeinoddini A, Emami SA, Akhondzadeh S. Celecoxib versus diclofenac in mild to moderate depression management among breast cancer patients: A double-blind, placebo-controlled, randomized trial. Ann Pharmacother. 2015; 49(9):953-61.

26. Santiago RM, Barbiero J, Martynhak BJ, Boschen SL, da Silva LM, Werner MF, Da Cunha C, Andreatini R, Lima MM, Vital MA. Antidepressant-like effect of celecoxib piroxicam in rat models of depression. J Neural Transm (Vienna). 2014; 121(6):671-82.

27. Mannaa SS, Umathe SN. Paracetamol potentiates the antidepressant-like and anticompulsive-like effects of fluoxetine. Behavioural Pharmacology. 2015; 26(3):268-81.

28. Lang UE, Borgwardt S.Molecular mechanisms of depression: perspectives on new treatment strategies. Cell Physiol Biochem. 2013; 31(6):761-77.

29. Karagiannides I, Golovatscka V, Bakirtzi K, Sideri A, Salas M, Stavrakis D, Polytarchou C, Iliopoulos D, Pothoulakis C, Bradesi S. Chronic unpredictable stress regulates visceral adipocyte mediated glucose metabolism and inflammatory circuits in male rats. Physiol Rep. 2014; 2(5):e00284.

30. Pekala K, Budzynska B, Biala G. Utility of the chronic unpredictable mild stress model in research on new antidepressants. Curr Issues Pharm Med Sci. 2014; 27(2):97-101.

31. Kanwal S, Ikram H, Farhan M, Haleem DJ. Apomorphine induced conditioned place preference and sensitization is greater in rats exposed to unpredictable chronic mild stress. Pak J Pharm Sci. 2015; 28(6):1927-32.

32. Yalcin İ, Belzunga C, Surget A. Mouse strain differences in the unpredictable chronic mild stress: a four-antidepressant survey. Behav Brain Res. 2008: 193(1):140-3.

33. Ibarguen-Vargas Y, Surget A, Touma C, Palme P, Belzung C, Multifaceted strain-specific effects in a mouse model of depression and of antidepressant reversal. Psychoneuroendocrin. 2008; 33(10):1357-68.

34. Stanley SC, Brooks SD, Butcher JT, d'Audiffret AC, Frisbee SJ, Frisbee JC. Protective effect of sex on chronic stress- and depressive behavior-induced vascular dysfunction in BALB/cJ mice. J Appl Physiol. 2014; 117(9): 959-70.

35. Bowman RE, Beck KD, Luinea VN. Chronic stress effects on memory: sex differences in performance and monoaminergic activity. Horm Behav. 2003; 43(1):48-59.

36. Frisbee JC, Brooks SD, Stanley SC, d'Audiffret, AC. An unpredictable chronic mild stress protocol for instigating depressive symptoms, behavioral changes and negative health outcomes in rodents. J Vis Exp. 2015; 106:53109.

37. Lan N, Hellemans KG, Ellis L, Weinberg J. Exposure to chronic mild stress differentially alters corticotropin-releasing hormone and arginine vasopressin mRNA expression in the stress-responsive neurocircuitry of male and female rats prenatally exposed to alcohol. Alcohol Clin Exp Res. 2015; 39(12):2414-21.

38. Franceschelli A, Sens J, Herchick S, Thelen C, Pitychoutis PM. Sex differences in the rapid and the sustained antidepressant-like effects of ketamine in stress-naïve and "depressed" mice exposed to chronic mild stress. Neuroscience. 2015; 290:49-60.

39. Surget A, Saxe M, Leman S, Ibarguen-Vargas Y, Chalon S, Griebel G, Hen R, Belzung C. Drug-dependent requirement of hippocampal neurogenesis in a model of depression and of antidepressant reversal. Biol Psychiatry. 2008; 15:64(4):293-301.

40. Hill AS, Sahay A, Hen R. Increasing Adult Hippocampal Neurogenesis is Sfficient to Reduce Anxiety and Depression-Like Behaviors. Neuropsychopharmacology. 2015;40(10):2368-78. 